\title{
A dimensão ambiental da educação geográfica
}

\section{Environmental dimension of geography education}

\author{
Sônia Maria Marchiorato Carneiro*
}

\begin{abstract}
RESUMO
O texto tem por objetivo delinear uma introdução ao desenvolvimento da dimensão ambiental da educação geográfica no ensino básico, em sentido de fundamentação e orientação prática. Para tanto, são relacionadas a Educação Ambiental e a geografia escolar, de um perspectiva sociopolítica ao contexto das decisões curriculares; e, neste âmbito, são postas algumas orientações pedagógico-metodológicas.

Palavras-chave: Dimensão ambiental, educação geográfica, orientações pedagógico-metodológicas.
\end{abstract}

\begin{abstract}
The text aims at introducing the development of the environmental dimension of geographical education for primary and secondary levels of the Brazilian school system, both as to fundaments and as well practical guidance. Thus, Environmental Education and school geography are interrelated, from a socio-political perspective to the context of cur-ricular decisions; and some pedagogic-methodological orientations are then presented.
\end{abstract}

Key-words: Environmenal dimension, geographical education, pedagogicmethodological orientations.

* Departamento de Teoria e Prática de Ensino, Setor de Educação da UFPR. Doutora em Meio Ambiente e Desenvolvimento, com tese na área de Educação Ambiental (1999). soniac@educacao.ufpr.br 
Na dinâmica das relações sociedade-natureza, as questões ambientais têm a ver com a qualidade de vida das pessoas, implicando os direitos de cidadania nos âmbitos individual e coletivo e, pois, envolvendo as necessidades de trabalho, moradia, alimentação, saúde, educação, informação e lazer com infra-estrutura adequada nos locais de habitação (água, luz e saneamento), condições de segurança e ambientes sadios, ou seja, livres de poluição e degradação; de mais a mais, priorizando a participação dos cidadãos na prevenção e resolução dos problemas socioambientais.

Dispositivos constitucionais asseguram que "todos têm direito ao meio ambiente ecologicamente equilibrado, bem de uso comum do povo e essencial à sadia qualidade de vida, impondo-se ao Poder Público e à coletividade o dever de defendê-lo e preservá-lo para as presentes e futuras gerações" (Constituição da República Federativa do Brasil, 1988, art. 225; ênfases aqui). Esta garantia constitucional de um princípio básico de cidadania, ainda continua, neste início da primeira década do século XXI, sem maior e tanto menos, plena, efetividade prática. Em compasso de acomodação, as demandas consumistas, mormente de sociedades mais ricas, o Brasil segue depauperando sua biosfera - por descuido com suas riquezas naturais e, pior, numa linha de interesses extrativistas e da expansão agrícola corporativa, juntamente com descaso para com a infra-estrutura da qualidade de vida dos cidadãos. ${ }^{1}$ Segundo o ministro colombiano de meio ambiente, Juan Mayr Maldonado, em pronunciamento quanto à urgência de uma Ética de Desenvolvimento, no Fórum de Ministros de Meio Ambiente da América Latina e Caribe, no Rio de Janeiro - outubro de 2001, [...] "os problemas ambientais continuam surgindo num ritmo muito maior que as suas soluções" (ambientebrasil.com.br $-28 / 10 / 2001)$.

A Educação, pelo seu intrínseco estatuto de compromisso socioambiental, é chamada mais que nunca - desde a emergência insofismável da questão do meio ambiente nos meados do século XX - a uma efetiva militância pedagógica pela qualidade de vida. Por isso, vêm-se fazendo necessárias, explicitamente no âmbito da educação escolar, formal novas orientações nos planos curriculares e na dinâmica didático-metodológica, envolvendo não só professores e alunos e o pessoal escolar em seu todo, mas também as relações escola-comunidade. Nesse sentido, duas medidas foram tomadas em nosso

1 Alguns indicadores mais recentes de problemas: o combate à venda ilegal de pássaros silvestres e de ginseng nativo da bacia do rio Paraná (município de Porto Rico-PR) e a "operação mogno"; as discussões parlamentares sobre agricultura transgênica, o Plano Nacional de Saneamento, os resíduos agrícolas e o asbesto/amianto (ambientebrasil.com.br-ago./nov. 2001). 
país no final da década de 1990, abrindo perspectivas de avanço ao processo educativo: a implementação, pelo Ministério da Educação e do Desporto, dos Parâmetros curriculares $\left(1^{\mathrm{a}}\right.$. $-4^{\mathrm{a}}$. séries, $1997 ; 5^{\mathrm{a}}$. $-8^{\mathrm{a}}$. séries, 1998), envolvendo a dimensão ambiental como um dos temas transversais nos programas curriculares do ensino fundamental; e a sanção, pelo Presidente da República, da Lei 9.795 (1999), que instituiu a Política Nacional de Educação Ambiental para todos os níveis e modalidades de educação e, portando, nos âmbitos formal e não-formal.

O tema transversal meio ambiente constitui uma das dimensões da educação escolar geral e, conseqüentemente, não pode ser visualizado como disciplina e sim como um enfoque de conteúdos socioambientais a serem trabalhados em todas as disciplinas - em proporção adequada de abrangência e aprofundamento de acordo com as séries e níveis de ensino. Com efeito, a educação ambiental é a própria educação escolar em seu objetivo fundamental de apoiar e orientar o desenvolvimento pelos alunos, enquanto cidadãos em formação, de uma nova mentalidade de interação com as questões ambientais, na perspectiva do senso e do compromisso - precisamente - de uma cidadania ambiental. Para tanto, a educação escolar, hoje, deve assumir a urgência de se desenvolver comprometida com a meta sociopolítica de preparar cidadãos capacitados, ética e intelectualmente, a responderem "aos desafios colocados pelo estilo de desenvolvimento dominante, a partir da construção de um novo estilo harmônico entre sociedade e a natureza e que, ao mesmo tempo, sejam capazes de superar a racionalidade meramente instrumental e economicista, que deu origem às crises ambiental e social que hoje nos preocupam" (Mininni Medina; SAntos, 2000, p. 24).

O contexto epistêmico para essa guinada de orientação da Educação, no Brasil, vem sendo construído nas últimas décadas, numa convergência de esforços internacionais e nacionais. Assim é que, sob um foco analíticoreferencial, a prática educativa quanto a conteúdos de meio ambiente na escola brasileira aponta as tendências ecológico-preservacionista e socioambiental, distintas em seus pressupostos, abrangência de objetivos e orientação metodológica - mas não excludentes, dado que a última configura uma superação incorporativa da primeira, em seus aspectos positivos de preocupação com a natureza (CARNEIRO, 1999, p. 53-55). A base epistemológica da identificação dessas tendências deriva-se da obra do prof. Enrique Leff, a partir da década de 1980, com foco na construção de uma racionalidade ambiental alternativa de desenvolvimento, entendendo a crise ambiental como degradação da qualidade de vida e buscando superar os limites do produtivismo 
neoliberal hegemônico - gerador de dependência tecnológica e da dicotomia desenvolvimento-subdesenvolvimento capitalista - pela proposta da necessidade da reapropriação social da natureza sob uma ótica de eqüidade e justiça; isto implica ir além das soluções técnicas de contaminação ambiental, incorporando os saberes populares, bem como a cosmovisão dos setores sociais marginalizados, na efetivação de tecnologias e práticas ecologicamente sustentáveis. ${ }^{2}$ As posições de Leff têm sido carreadas pela profa ${ }^{\text {. }}$ Naná Minnini Medina ao campo da Educação Ambiental no Brasil, por meio de cursos de formação ${ }^{3}$ e publicações $(1994,2000)$.

A educação para a sustentabilidade ambiental é mais que uma prioridade meramente curricular, que pudesse ser efetivada por decisões referentes a conteúdos de ensino-aprendizagem e a mediações metodológicas, com seus recursos instrumentais; em realidade, trata-se de um processo amplo, com substantivas implicações epistemológicas e político-culturais e que, ao mesmo tempo, se constrói como uma nova orientação - senão concepção - pedagógica e orienta as práticas educativas escolares. Desse modo, a dimensão dessas práticas indicada como educação ambiental integra, necessariamente, uma dinâmica pedagógico-metodológica compromissada com a questão da sustentabilidade, sob o foco de uma tríplice qualificação:

- $\quad$ interdisciplinar: pelo fato de que a questão ambiental, pela sua natureza complexa, não pode ser tratada apenas no âmbito de uma disciplina ou área de conhecimento;

2 Enrique Leff, professor da Universidade Nacional Autonoma do México-Unam, coordena a Rede de Formação Ambiental da América Latina e Caribe do PNUD, sendo também professor do Curso de Doutorado em Meio Ambiente e Desenvolvimento da UFPR; para explicitação da síntese posta nesse primeiro parágrafo da página corrente, ver o livro do autor em foco: Ecologia, capital e cultura. Racionalidade ambiental, democracia participativa e desenvolvimento sustentável. Blumenau: Editora da FURB, 2000. Uma coletânea de artigos do autor, desde 1981 a 2000, foram organizados e/ou reescritos em livro, também publicado em português: Epistemologia ambiental. São Paulo: Cortez, 2001.

3 Inclusive no Paraná: em julho de 1995, a prof $^{a}$. Medina trabalhou, em perspectiva teórica, um curso tematizado como Capacitação em educação ambiental, sob auspícios da SEED-PR; além de participar de e/ou desenvolver cursos de especialização e capacitação de pessoal (técnico e docente) de nível superior, patrocinados pelo MEC na área de Educação ambiental, a prof ${ }^{\mathrm{a}}$. Medina foi consultora do Projeto dos Parâmetros curriculares, iniciado em 1995. Tem participado de bancas de defesa de teses, no Curso de Doutorado em Meio Ambiente e Desenvolvimento da UFPR. 
- crítica: enquanto são requeridos critérios pertinentes, de cunho científico, tecnológico, sociopolítico, cultural e ético para o questionamento de informações e a investigação de dados e fatos ambientais;

- $\quad$ prospectiva: pela capital importância da relação presente-futuro, em termos do vínculo ético das gerações atuais para com as vindouras quanto à qualidade de vida.

A efetivação interdisciplinar, crítica e prospectiva da dimensão ambiental da educação escolar requer, por parte do educador, não apenas um conhecimento, o mais explícito possível e sim uma vivência reflexiva, na interação com os alunos, de três princípios fundamentais, respectivamente nos planos ético, conceitual e metodológico (CARNEIRO, 1999, p. 56-76):

- plano ético: responsabilidade, enquanto princípio emergente da própria história da Educação Ambiental - sob o pressuposto de que a crise ambiental origina-se da conduta humana eticamente desreferenciada em relação à natureza;

- plano conceitual: o princípio da interdependência, de validade ecológico-científica e como referencial no contexto das relações sociedadenatureza - dado que não só o homem depende do meio natural, mas que também este tem passado crescentemente a depender do homem para ser mantido como adequado à vida;

- plano metodológico: o princípio norteador é o da interdisciplinaridade, já anteriormente chamado num nível mais amplo destas colocações; no nível das práticas escolares, em conexão às questões ambientais - que por definição são sempre sociais - este princípio referencia o diálogo e a busca de integração participativa dos sujeitos (pessoal escolar, os alunos e as próprias comunidades) nos processos educativos, pela troca de experiências na construção dos conhecimentos e nas tomadas de decisões.

A prática educativa escolar, sob a ótica da sua dimensão ambiental, envolve possibilidades inovadoras em todas áreas de conhecimento ou disciplinas específicas, a iniciar com a novidade de uma leitura diversificada e complementar das questões socioambientais por educadores e educandos e, simultaneamente, pela experiência da construção de conhecimentos significativos e valiosos em sua relação com a realidade de vida; como decorrência, os alunos experimentarão, com uma maior concretude, a crescente percepção de um sentido unitário dos programas curriculares. Nesta linha, a educação geográfica também pode contribuir para uma desejável efetivação da dimensão ambiental da educação escolar 
A Geografia, enquanto ciência que trata do espaço no contexto das relações sociedade-natureza, busca explicitar a realidade de vida das populações quanto à dimensão espacial dos fenômenos, no sentido de onde ocorrem, como ocorrem e por que ocorrem: não somente localiza os elementos físicos e humanos sobre a superfície terrestre, como analisa as dinâmicas inter-relacionais desses elementos em diversas escalas, conforme os objetivos de estudo (local, regional, nacional e mundial) e as razões das interações, sob enfoques de compreensão criteriosa dos determinantes da construção organizacional do espaço pelo homem. Assim, a ciência geográfica comporta uma explícita relação com as interdependências do homem e do meio e, ainda mais, com as conseqüências dessa interação sobre o próprio espaço envolvente (CARneiro, 1993, p. 122; Alexandre; Diogo, 1997, p. 39).

A geografia escolar, a partir do sentido da Geografia enquanto ciência, guarda uma íntima relação com a Educação Ambiental. Pelo seu papel formativo no desenvolvimento do educando, ao orientá-lo na leitura do espaço, desde o imediato ao mais remoto, a educação geográfica envolve-se, motivada e justificadamente nos dias de hoje, com as questões ambientais. No trato das dinâmicas naturais e das relações entre sociedade e natureza, emergem problemas de várias dimensões, até por experiência dos alunos, que levam a questões de preservação e conservação ambiental e, pouco a pouco, à construção de uma compreensão da sustentabilidade ambiental - em conexão com atitudes e habilidades práticas relativas ao ambiente de vida dos alunos.

A formação de um raciocínio geográfico pelo educando é o objetivo fundante da geografia escolar: desde a identificação e a distribuição de elementos no espaço vital, passando pela apreensão de fenômenos sob crescentes representações escalares, pela apreeensão de relações causais de localização e variações espaciais e alcançando a compreensão das formas de organização e construção humana do espaço, no contexto das relações sociedade-natureza. Nessa seqüência progressiva de amplitude cognitiva e de penetração analítico-interpretativa, o educando estará se capacitando a ser um ator situado no mundo enquanto espaço relacional. Ao pensar relações geográficas também estará apreendendo e pensando interdependências ambientais, na perspectiva de mudanças e transformações desejáveis, por meio de estratégias adequadas, em vista de estilos de desenvolvimento socioeconômico compatíveis com a qualidade de vida, nos âmbitos locais e em diferentes lugares, povos ou nações. E aí entra a atuação da escola, do professor, da professora de Geografia, para valorizar o tempo curricular desta disciplina como educação geográfica - na linha de um compromisso profissional, portanto competente e ético, para com a efetivação da dimensão 
ambiental da educação escolar (Mérenne-SchoumaKer, 1994, p. 31-32; Alexandre; Diogo, 1997, p. 45-47).

A capacitação do aluno em raciocinar geograficamente não pode se limitar ao âmbito puramente cognitivo, ou seja, a um trabalho relacional e interpretativo sobre informações e dados para uma leitura de mundo, por mais exata e objetiva que seja; tal raciocínio também será julgamento crítico, referenciado a valores e voltado a concretudes da realidade de vida das populações, sob os aspectos de diferentes condições físicas, sociais, culturais, econômicas e políticas, para que o educando tenha oportunidade de refletir com os colegas e professor(a) de Geografia sobre as potencialidades e desigualdades de lugares e regiões, bem como sobre seus problemas de meio ambiente. Esta orientação da educação geográfica favorecerá ao educando a formação de uma consciência espacial de qualidade ética, que é, em outros termos, uma consciência de cidadania ambiental - voltada a tomadas de decisões responsáveis quanto ao meio como patrimônio de todos, em termos de respeito para com a vida, a biodiversidade e a diversidade cultural. O exercício da prática de direitos e deveres em prol da qualidade de vida, já a partir do ambiente da escola e das suas comunidades, é condição imprescindível para que os educandos desenvolvam a consciência de participação política, sob a perspectiva de solidariedade e colaboração na prevenção e solução de problemas. O senso de responsabilidade para com a qualidade de vida e sua manutenção em vista das gerações presentes e futuras, evidentemente, se forma a longo prazo, no decorrer da experiência escolar do educando enquanto vivência de cidadania em construção, por referência a critérios assumidos e testemunhados pelos educadores. Assim, a educação geográfica será também uma capacitação do educando a uma leitura axiologicamente referenciada do mundo, envolvendo a progressiva compreensão conceitual e a construção de alguns critérios não somente de abrangência cognitiva e sensibilizadora, mas de conotação jurídica - no contexto da hodierna legislação ambiental brasileira e da ordem jurídica internacional (CARNEIRO, 1999, p. 60-62):

- a justiça equitativa: como equilíbrio de direitos e deveres, para o acesso igualitário às riquezas naturais e para a integridade dos sistemas ambientais, nos processos de desenvolvimento, desde âmbitos locais aos mais amplos;

- a prudência: como decisões de precaução ante riscos de prejuízos ambientais irreversíveis, buscando-se tanto uma viabilidade ecológica (balanço de bens não-renováveis e renováveis - os impactos ambientais) quanto espacial (distribuição de ocupação/utilização de ambientes populações, indústria, agricultura, reservas etc.); 
- e a honestidade: como coerência e integridade dos gestores da biosfera nas políticas de desenvolvimento, para a superação de reducionismos mercadológicos e desvios burocráticos, respeitando-se a própria veracidade de informações como bem comum.

A valorização da dimensão ambiental da educação geográfica demanda, igualmente, uma dinâmica pedagógico-metodológica adequada à fundamentação delineada anteriormente. Como orientação ampla, recomenda-se uma metodologia de problematização, pela qual professores e alunos interagem na elaboração de conteúdos significativos no quadro de tematizações geográfico-ambientais, a partir dos próprios programas curriculares vigentes, mas e aí está a diferença -, sob uma perspectiva interessada nas concretudes da experiência vital das comunidades dos alunos e dos entornos das escolas. E isso não apenas para efeito de uma dinâmica motivacional, porém em termos de uma diretiva básica compromissada com a diagnose, a prevenção e a solução de problemas socioambientais. Nesse sentido, procura-se ir além de um aproveitamento do meio ambiente como recurso didático, para trabalhar informações na construção de conhecimentos e formação de atitudes (inclusive pelos próprios educadores!) mediante um processo educativo sobre, através e a favor do meio, enquanto espaço vital dos sujeitos (Sureda; Colom, 1989, p. 31-49) - passando-se "do estudo do meio à pedagogia do meio ambiente" (GiolitTo, 1982, p. 89). Algumas explicitações orientadoras, nessa linha, podem ser consideradas como critérios de referência global (CARNEIRO, 1999, p. 70-76):

- $\quad$ mais uma vez, a interdisciplinaridade: as situações ambientais comportam múltiplos enfoques de análise e compreensão - de modo que a educação geográfica terá que se desenvolver, na perspectiva ambiental, em diálogo com as demais áreas ou disciplinas curriculares, correlacionando os aportes das categorias espaciais com aspectos históricos, quantitativos, culturais e da área de ciências (fenômenos físicos, químicos e biológicos - sobretudo em sua convergência sob o ponto de vista da Ecologia);

- $\quad$ a gradualidade de leitura do espaço: a consideração dos níveis de maturidade cognitiva e afetivo-valorativa dos educandos, segundo as faixas etárias e as seriações curriculares, no desenvolvimento dos processos de apreensão-identificação, análise-compreensão e avaliação-decisão dos fatos e/ou fenômenos, em sua configuração e dinâmica espácioambiental; importante ainda, nesse critério, é levar em conta a procedência e local de residência dos alunos (áreas rurais ou urbanas, em 
suas concretudes diferenciais), bem como os níveis sociocultural e econômico das suas famílias;

- e a flexibilidade/pluralidade: de procedimentos de ensino e aprendizagem: uma orientação metodológica para a solução/resolução de problemas, não só num plano cognitivo como em perspectiva de aplicação prática, envolve um aproveitamento - referencialmente criterioso - de todas as técnicas e recursos disponíveis, sobretudo num foco de abertura à invenção e à criatividade frente às condições reais da ação pedagógica e, igualmente, segundo os momentos ou fases dos programas, projetos e processos educativos e tendo-se em conta os seus objetivos e sujeitos envolvidos.

A educação geográfica, como prática pedagógica numa linha problematizadora, terá encaminhamento efetivo mediante a elaboração de um projeto de educação geográfica na perspectiva da dimensão ambiental, levando em conta as orientações postas, enquanto complementares e mutuamente implicadas. Esse projeto será intra-e-interdisciplinar, na situação da estrutura disciplinarista dos currículos escolares atuais: cada professor(a) trabalhará os conteúdos do programa de Geografia em seu significado ambiental - desde as dinâmicas da natureza e as relações sociedade-natureza até políticas de sustentabilidade ambiental - e, simultaneamente, desenvolvendo processos de interação, de diálogo, com os professores das demais disciplinas; e isto, não só pelo(a) professor(a), mas também pelos alunos, no sentido de se levantar diferentes pontos de vista sobre um problema ou uma questão ambiental, de acordo com a perspectiva de apreensão e análise de cada disciplina. Desse modo, os alunos poderiam contribuir com sua experiência de vida nas próprias comunidades, orientados previamente sobre os objetos, âmbito e abrangência de suas observações ou investigação. $\mathrm{O}$ (a) professor(a) coordenará o aproveitamento do material informativo em termos de organização lógica e de interpretação relacional, apoiando os alunos na linha de uma participação produtiva Além deste projeto referencial, projetos mais específicos sobre tema e/ou problemas concretos, de sentido regional e/ou comunitário e, especialmente, envolvendo as escolas e seus entornos, poderiam ser desenvolvidos pelo conjunto dos professores. Estes projetos deverão captar a participação de atores da comunidade, incluindo membros de associações locais, empresas, órgãos administrativos etc.

Os temas de investigação, tanto numa amplitude intra como interdisciplinar, devem envolver problemas reais, em termos de "uma discrepância entre o que acontece e o que seria desejável que se verificasse" 
(Alexandre; Diogo, 1997, p. 88). As fases processuais dos projetos, segundo esses autores (Ibid., p. 88-93), são: as de preparação, de realização e de avaliação.

A fase de preparação envolve, inicialmente, a identificação de um problema, sob um ponto de vista temático (habitação, infra-estrutura socioadministrativa, aspectos naturais, agricultura, indústria, comércio etc.) por meio de um levantamento prévio, de um inventário entre professor(a) e alunos, considerando o programa curricular de cada série, sempre em conexão com as concretudes dos locais de vida dos alunos (necessidades, condições, interesses das suas comunidades). O segundo momento desta fase de preparação corresponde à planificação do trabalho, incluindo: delimitação da áreas de estudos e os aspectos a serem investigados; seleção dos procedimentos para a coleta de informações (técnicas adequadas e recursos/meios requeridos: roteiros de opinionário/questionário, de entrevista, de observação, de levantamentos a partir de fontes noticiosas etc.; utilização de mapas e fotografias etc.); distribuição de tarefas a grupos/equipes de alunos, segundo as áreas e aspectos do problema; e escalonamento do tempo necessário e/ou disponível para execução do projeto, com as convenientes margens de flexibilidade (mínimo e máximo de horas a serem alocadas).

A fase de realização compreende, num primeiro momento, o levantamento de dados (pela operacionalização dos procedimentos selecionados), a análise (agrupamento e classificação/categorização descritiva) e a interpretação das informações (avaliação e discussão de aspectos mais relevantes, sob vários pontos de vista/critérios - saberes, práticas populares e princípios de raciocínio geográfico e ambiental, sob a perspectiva de diagnose, prevenção e solução de problemas); nesse trabalho de interpretação, os alunos produzem textos, elaboram mapas e gráficos diversos, ilustrações e desenhos, maquetes e criam jogos simulativos etc. Num segundo momento, os resultados serão apresentados e discutidos em classe, em vista de uma compreensão global do problema pelos alunos quanto às inter-relações causais nas situações estudadas, e ainda, possíveis ações de solução ou de prevenção; este processo interativo-comunicativo será objetivado em texto ou textos de síntese, por uma equipe representativa de todas as equipes, com a colaboração do(a) professor(a). Um terceiro momento desta fase de realização do projeto comportará a apresentação dos resultados à escola como um todo e à comunidade (em sentido amplo - não apenas às famílias dos alunos), com valorização do trabalho das equipes, sob formas adequadas ao tema e ao nível dos alunos: cartazes e murais, jornal escolar, exposição, conferência, debate, dramatização etc. 
A terceira fase projeto, avaliação, será conduzida em forma de uma auto e heteroavaliação por parte dos alunos e professor(a), quanto às atividades desenvolvidas, aos resultados obtidos, às dinâmicas de relacionamento, ao envolvimento dos atores; assim como em relação às facilidades e dificuldades encontradas e, igualmente, às decisões tomadas para a superação dessas dificuldades e prospectivas sobre novo(s) projeto(s).

Para um aproveitamento de maior alcance dos resultados, cada projeto poderá ser ponto de partida para reivindicações cívicas relacionadas à melhoria e/ou manutenção das condições de vida das populações, envolvendo associações de bairro, empresas, clubes, igrejas, bem como cidadãos representativos, em vista de gestões junto a órgãos administrativos para iniciativas conjuntas; possíveis formas de ação, entre outras: campanhas, abaixo-assinados, passeatas, matérias em jornais e rádios locais, cartas para autoridades (inclusive, de punho dos alunos), circulação de panfletos, visitas domiciliares e a órgãos ou instituições (mais uma vez, inclusive por alunos).

A valorização da geografia escolar, enquanto educação geográfica, passa por propostas expressivas do seu mérito curricular na formação intelectual e atitudinal dos educandos. Tais propostas, pela natureza mesma da Geografia, serão tanto mais significativas e urgentes no contexto da problemática ambiental de nossos dias. As próprias diretivas oficiais já não desconhecem o peso desta urgência - haja vista a proposta ministerial do tema transversal de meio ambiente nos diferentes conteúdos curriculares da escola fundamental. Nesse sentido, a criatividade de cada professor(a), com seus alunos, sua escola e comunidade, se defronta com os desafios reais postos pelas potencialidades e problemas de cada realidade ambiente e, tanto mais por isso mesmo, tem que se afirmar em termos de competência profissional na linha de uma educação para a cidadania. Desse modo, quaisquer orientações de fundamentação pedagógico-didática será sempre instrumental e referencial para a ação de cada educador(a), cabendo-lhe concretizar suas propostas de trabalho local e institucionalmente significativas.

Ao educador(a) brasileiro(a), na sua condição também latino-americana, a responsabilização socioambiental se coloca como diferença na luta por uma sociedade mais humana e igualitária - não sendo bastante um empenho pela conservação da natureza, como é a maior preocupação dos países mais desenvolvidos. ${ }^{4}$ Daí que, a efetivação da educação geográfica em

4 Nos EUA e Canadá, assim como na Europa e Austrália, há uma forte vinculação da Educação Ambiental (EA) com a conservação da natureza ("the green wave"; a tendência ecológico-preservacionista nos estudos brasileiros) na educação formal, escolar, distanciada 
perspectiva da dimensão ambiental, partilha do compromisso comum de formar cidadãos conscientes e participativos, mas sob o enfoque específico da espacialidade dos problemas: assim, a pergunta quem sou? se desdobra em onde estou? onde vivo? para chegar a como posso/devo agir? A escola, como lugar privilegiado de preparação da e para a cidadania, mediante já sua prática, oportuniza ao agente da educação geográfico-ambiental a gratificante tarefa de garantir a seus alunos um espaço educativo bem evocado por AleXANDre e Diogo (1997, p. 98):

No contato com os colegas, professores, pais, forças vivas da comunidade, representantes autárquicos etc., os alunos têm oportunidade de divulgar os resultados de suas investigações, fazer ouvir suas idéias e propostas $e$, dessa forma, sentirem-se elou tornarem-se cidadãos socialmente participativos e empenhados na resolução de problemas que afetam a comunidade onde se inserem ou, num contexto mais amplo, os que afetam a sociedade ou planeta em que vivemos. ${ }^{5}$

\section{REFERÊNCIAS}

ALEXANDRE, F.; DIOGO, J. Didáctica da Geografia. Contributos para uma educação no ambiente. 3. ed. Lisboa: Texto, 1997.

BRASIL. Constituição da República Federativa do Brasil. Brasília: Senado Federal, Centro Gráfico, 1988.

. Ministério da Educação e do Desporto. Parâmetros curriculares nacionais: meio ambiente, saúde. Brasília: Secretaria de Educação Fundamental, 1998.

dos processos comunitários e dos problemas econômicos e questões socioculturais específicas; já nos países em desenvolvimento, particularmente na América Latina, a EA tem tido um enfoque mais inclusivo, com articulações sociais (GAUDIANO, 1999, p. 20).

5 Grafia segundo a norma brasileira. 
. Lei N. ${ }^{0} 9.795$ de 27 de abril de 1999. Dispõe sobre a educação ambiental, institui a Política Nacional de Educação Ambiental e dá outras providências. Diário Oficial da República Federativa do Brasil, Brasília, n. 79, 28 abr. 1999.

CARNEIRO, S. M. M. A importância educacional da Geografia. Educar em Revista, Curitiba: Editora da UFPR, n. 9, p. 121-125, 1993.

. A dimensão ambiental da educação escolar de $1^{a}$.- $4^{a}$. séries do ensino fundamental na rede escolar pública da cidade de Paranaguá. Curitiba, 1999. Tese (Doutorado) - Universidade Federal do Paraná.

GAUDIANO, E. G. Otra lectura a la historia de la Educación Ambiental en América Latina y el Caribe. Tópicos en Educación Ambiental, v. 1, n. 1, p. 9-26, 1999.

GIOLLITO, P. Pédagogie de l'environnement. Paris: Presses Universitaires de France, 1982.

LEFF, E. Ecologia, capital e cultura. Racionalidade ambiental, democracia participativa e desenvolvimento sustentável. Blumenau: FURB, 2000.

MEDINA, N. M. Elementos para a introdução da dimensão ambiental na educação escolar - $1^{\circ}$. grau. In: BRASIL. Ministério do Ambiente e da Amazônia Legal/Instituto Brasileiro do Meio Ambiente e dos Recursos Naturais Renováveis. Amazônia: uma proposta interdisciplinar de educação ambiental. Documentos metodológicos. Brasília: Ibama, 1994.

. SANTOS, E. C. Educação ambiental. Uma metodologia participativa de formação. Petrópolis: Vozes, 2000.

MÉRENNE-SCHOUMAKER, B. Didactique de la Géographie. Paris: Éditions Nathan, 1994.

NOAL, F. O. et al. (Org.). Tendências da Educação Ambiental Brasileira. Santa Cruz do Sul: UNISC, 1998.

SUREDA, J.; COLOM, A. J. Pedagogía ambiental. Barcelona: Ediciones CEAC, 1989.

Texto recebido em 10 de fev. 2002 Texto aprovado em 22 de abr. 2002 